\title{
Progesterone Induces the Growth and Infiltration of Human Astrocytoma Cells Implanted in the Cerebral Cortex of the Rat
}

\author{
Liliana Germán-Castelán,, Joaquín Manjarrez-Marmolejo, ${ }^{2}$ Aliesha González-Arenas, \\ María Genoveva González-Morán, ${ }^{3}$ and Ignacio Camacho-Arroyo ${ }^{1}$ \\ ${ }^{1}$ Facultad de Química, Departamento de Biología, Universidad Nacional Autónoma de México, Ciudad Universitaria, \\ Coyoacán, 04510 Ciudad de México, DF, Mexico \\ ${ }^{2}$ Laboratorio de Fisiología de la Formación Reticular, Unidad de Investigaciones Cerebrales, \\ Instituto Nacional de Neurología y Neurocirugía MVS, 14269 Ciudad de México, DF, Mexico \\ ${ }^{3}$ Facultad de Ciencias, Laboratorio de Biología de la Reproducción animal, Departamento de Biología Comparada, \\ Universidad Nacional Autónoma de México, Ciudad Universitaria, Coyoacán, 04510 Ciudad de México, DF, Mexico \\ Correspondence should be addressed to Ignacio Camacho-Arroyo; camachoarroyo@gmail.com
}

Received 11 February 2014; Accepted 7 May 2014; Published 22 May 2014

Academic Editor: Betty Tyler

Copyright (C) 2014 Liliana Germán-Castelán et al. This is an open access article distributed under the Creative Commons Attribution License, which permits unrestricted use, distribution, and reproduction in any medium, provided the original work is properly cited.

\begin{abstract}
Progesterone $\left(\mathrm{P}_{4}\right)$ promotes cell proliferation in several types of cancer, including brain tumors such as astrocytomas, the most common and aggressive primary intracerebral neoplasm in humans. In this work, we studied the effects of $\mathrm{P}_{4}$ and its intracellular receptor antagonist, RU486, on growth and infiltration of U373 cells derived from a human astrocytoma grade III, implanted in the motor cortex of adult male rats, using two treatment schemes. In the first one, fifteen days after cells implantation, rats were daily subcutaneously treated with vehicle (propylene glycol, $160 \mu \mathrm{L}$ ), $\mathrm{P}_{4}(1 \mathrm{mg})$, RU486 (5 mg), or $\mathrm{P}_{4}+\mathrm{RU} 486$ (1 mg and $5 \mathrm{mg}$, resp.) for 21 days. In the second one, treatments started 8 weeks after cells implantation and lasted for 14 days. In both schemes we found that $\mathrm{P}_{4}$ significantly increased the tumor area as compared with the rest of the treatments, whereas RU486 blocked $\mathrm{P}_{4}$ effects. All rats treated with $\mathrm{P}_{4}$ showed tumor infiltration, while $28.6 \%$ and $42.9 \%$ of the animals treated with RU486 and $\mathrm{P}_{4}+$ RU486, respectively, presented it. Our data suggest that $\mathrm{P}_{4}$ promotes growth and migration of human astrocytoma cells implanted in the motor cortex of the rat through the interaction with its intracellular receptor.
\end{abstract}

\section{Introduction}

Astrocytomas are the most common and aggressive primary intracerebral tumors. They arise from astrocytes, glial progenitor cells, or cancer stem cells [1-5] and they are classified by the World Health Organization (WHO) in four grades (I-IV) according to their histological characteristics such as mitotic activity, nuclear atypia, cellularity, vascularity, and necrosis [6-8]. Anaplastic astrocytoma (WHO grade III) and glioblastoma (WHO grade IV) are the most frequent and malignant brain tumors in world population. They are characterized by high mitotic activity, nuclear atypia, and infiltrative lesions [9], and prognosis depends on multiple factors such as size, localization, and evolution time; however, generally, the survival of patients is very brief (24-36 months in anaplastic astrocytoma and less than 12 months in glioblastoma $[10,11])$. Current medical treatments such as neurosurgery, radiotherapy, and chemotherapy achieve only a modest improvement in the length of survival and quality of life of patients [12-14].

Progesterone $\left(\mathrm{P}_{4}\right)$ is a steroid hormone derived from cholesterol that regulates several functions such as sexual behavior, pregnancy, and neuroprotection, and it has also been related to cancer progression [15-17]. $\mathrm{P}_{4}$ exerts many of its effects through the interaction with its intracellular receptor (PR) which is a ligand-activated transcription factor $[18,19]$. It has been reported that PR expression directly correlates with astrocytomas evolution grade, suggesting that PR-positive tumors present a high proliferative potential [20, 21]. 


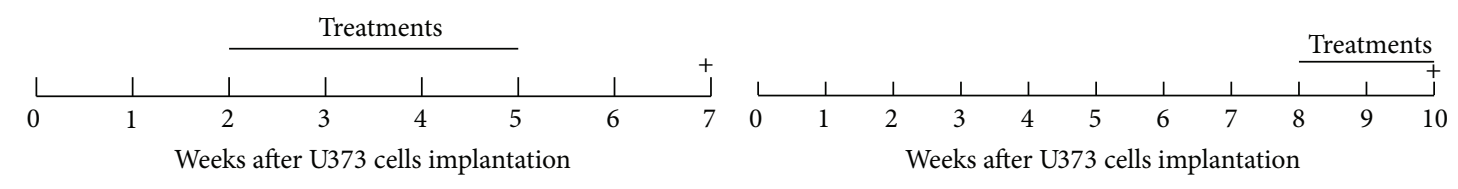

(a)

(b)

FIGURE 1: Scheme of treatments administered to the rats implanted with U373 cells in the motor cortex. (a) Short progression. (b) Long progression. + indicates the euthanasia.

It has been demonstrated that $\mathrm{P}_{4}$ promotes astrocytomas growth [22-25] and that the administration of RU486 (PR antagonist) blocks $\mathrm{P}_{4}$ effects [23, 26-28]. It has also been reported that RU486 improves the efficacy of chemoradiotherapy in glioblastoma xenografts in mice [29]. Previous studies about the role of $\mathrm{P}_{4}$ in astrocytoma cell lines proliferation in vitro have shown that $\mathrm{P}_{4}$ increases cell growth, as well as the expression of genes involved in cell cycle progression and metastasis such as cyclin D1, EGFR, and VEGF [30]; however, no in vivo studies have been performed. In this work, we studied the effects of $\mathrm{P}_{4}$ on tumor progression of U373 cells derived from a human astrocytoma grade III implanted in the motor cortex of the rat.

\section{Materials and Methods}

2.1. Cell Line and Culture. U373 astrocytoma cell line derived from a human astrocytoma grade III (ATCC, Manassas, VA) was maintained in Dulbecco's modification of Eagle's medium (DMEM) supplemented with 10\% fetal bovine serum, $1 \mathrm{mM}$ pyruvate, $2 \mathrm{mM}$ glutamine, and $0.1 \mathrm{mM}$ nonessential amino acids, all from Gibco (Grand Island, NY), at $37^{\circ} \mathrm{C}$ in a humidified atmosphere with 95\% air/5\% $\mathrm{CO}_{2}$. DMEM was changed every 48 hours until reaching $70-80 \%$ cellular confluence.

2.2. Implantation of Tumor Cells in the Rat Brain. The Wistar adult male rats (250-300 g) maintained on a $12: 12$ light/dark cycle with food and water ad libitum were intraperitoneally anesthetized with ketamine-xylazine $(80 / 10 \mathrm{mg} / \mathrm{kg}$ resp.) and mounted in a stereotaxic apparatus. The head was cleaned and shaved, and the scalp was incised in the anteroposterior direction exposing the skull. Small holes were drilled in the left side of skull and a stainless-steel guide cannula (21-gauge) was inserted at the coordinates: Bregma AP $=1.6 ; L=3.0$, $2 \mathrm{~mm}$ above the injection site (motor cortex) according with the Paxinos and Watson atlas [31]. 120,000 U373 cells in a volume of $2 \mu \mathrm{L}$ of DMEM were slowly injected during a $2 \mathrm{~min}$ period using an injection cannula (25-gauge) inserted into the guide cannula connected through a polyethylene tube. The injection cannula that protruded $2 \mathrm{~mm}$ of guide cannula was maintained in the injection site for 5 more minutes after the injection. The hole bone was sealed using bone wax, and rats were given a dose of enrofloxacin $(10 \mathrm{mg} / \mathrm{kg})$ during 48 hours. All animal procedures were performed as per the following guidelines: (i) the Neurology and Neurosurgery National Institute's Ethical Code for the care and use of laboratory animals and (ii) Mexican guidelines for the production, care, and use of laboratory animals (NOM-062-ZOO-1999). The animals were maintained in the vivarium conditions until they were used.

2.3. Treatments. Rats were randomly divided into four groups (7 rats/group), and each group was assigned to the following subcutaneous treatments $\left(\mathrm{P}_{4}\right.$ and RU486 were dissolved in propylene glycol): vehicle ( $160 \mu \mathrm{L}$ of propylene glycol) (Baker Analyzed, Center Valley, PA); $1 \mathrm{mg}$ of $\mathrm{P}_{4}$ (RBI, Natick, MA); 5 mg of RU486 (SIGMA, St. Louis, MO); or $1 \mathrm{mg}$ of $\mathrm{P}_{4}+5 \mathrm{mg}$ of RU486. We performed two treatment schemes (Figure 1). In the first one (short progression), steroids were daily administered for 21 days, starting on day 15 after U373 cells implantation, and rats were euthanized 15 days after the last treatment. In the second scheme (long progression), we selected another 4 groups (2 rats/group) divided into the same way as described above, but the treatments started 8 weeks after U373 cells implantation; they lasted 14 days and the rats were euthanized one day after the last treatment.

2.4. Histology. Each rat was perfused with saline followed by $4 \%$ paraformaldehyde. Brains were removed and immersed in $4 \%$ paraformaldehyde at room temperature for 2 weeks. Afterwards, the brains were stored in sucrose gradient solutions $(10 \%, 20 \%$, and $30 \%)$ at room temperature for 24 hours each. Brain sections ( $10 \mu \mathrm{m}$ thick) were cut in the coronal plane around the implant site using a cryostat Leica CM1850 (Hesse, Germany). Some sections were stained by the Nissl method and examined in an Olympus Bx43 microscope (Tokyo, Japan).

2.5. Immunofluorescence. Another set of brain sections was blocked in $10 \%$ normal goat serum $/ 0.05 \%$ Tween-PBS (blocking buffer) 1 hour at room temperature and incubated at $4^{\circ} \mathrm{C}$ overnight with primary antibodies that identified glioma and proliferating cells, respectively: mouse Anti SOX2 (1:50) (sc-365964, Santa Cruz Biotechnology, Dallas, TX) and rabbit Anti-Ki-67 (1:400) (Ab9260, Chemicon International, Temecula, CA) in blocking buffer. The antibodies were removed and the sections were washed three times with 0.05\% Tween-TBS for 10 minutes and then incubated 1 hour at room temperature with secondary antibodies: Alexa 594 A-21203 (1:500) (Life Technologies, Carlsbad, CA) and FITC sc-2078 (1:500) (Santa Cruz Biotechnology, Dallas, TX). Nuclei were stained with Hoestch 33342 (Thermo Scientific, Waltham, MA). Sections were covered from light, washed, mounted with Fluoro Care Anti-Fade Mountant (Biocare Medical, Concord, CA), and visualized in an Olympus Bx43 


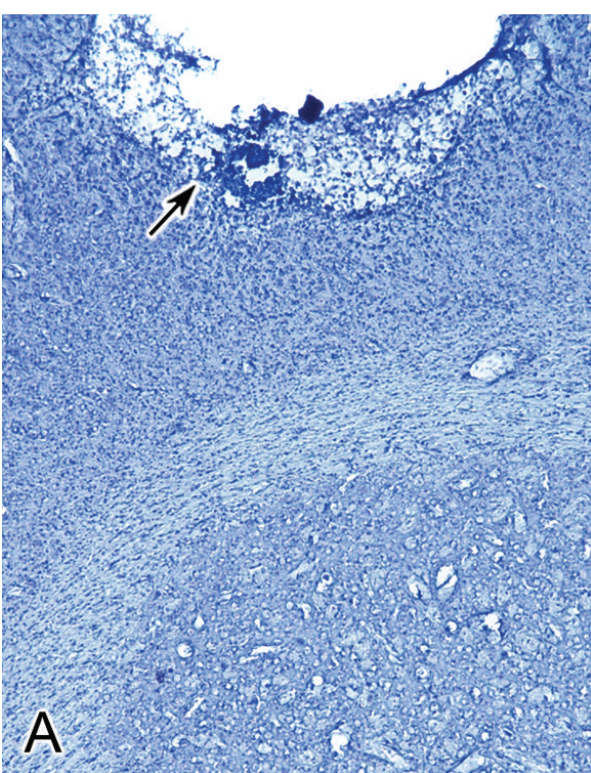

(a)



(c)

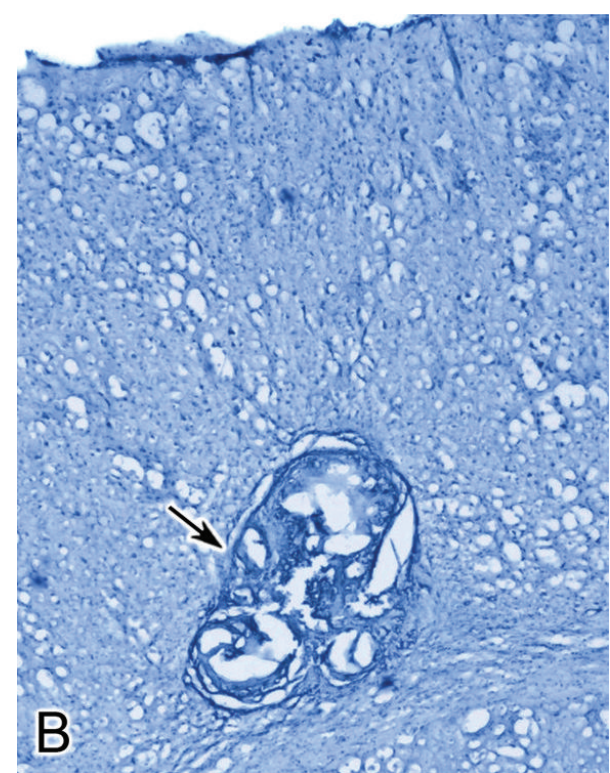

(b)

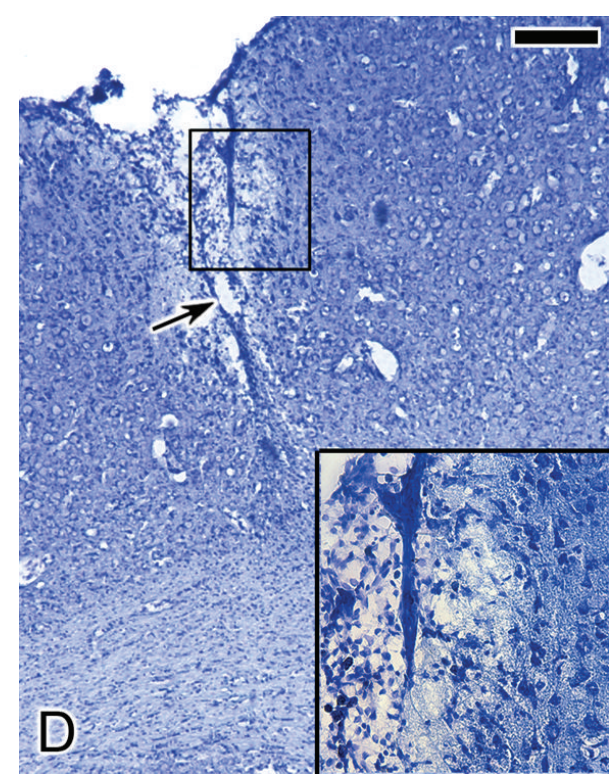

(d)

FIGURE 2: Effects of $\mathrm{P}_{4}$ and RU486 on the growth and infiltration of U373 human astrocytoma cells implanted in the motor cerebral cortex of the rat. Vehicle (propylene glycol) (a); $\mathrm{P}_{4}$ (b); RU486 (c); $\mathrm{P}_{4}+\mathrm{RU} 486$ (d). Tumor cells are marked with an arrow. Magnification is represented by $200 \mu \mathrm{m}$ scale in (a)-(d) and by $100 \mu \mathrm{m}$ scale in the inserts (c)-(d).

fluorescence microscope. The tumor area and its infiltration length were quantified by using the program Image-Pro Plus 7.0 Media Cybernetics (Rockville, MD). The considered tumor area was the largest one of all the sections obtained from each brain, and the infiltration length was measured from the implant site to the longest distance reached by astrocytoma cells.

2.6. Statistical Analysis. Data from tumor area were analyzed by using ANOVA followed by the Bonferroni test for the comparison between groups. Infiltration length data were analyzed by using chi-square test. Prism 5.0 (GraphPad, San Diego, CA) was used for calculating probability values.

\section{Results}

In this work, we studied the effects of $\mathrm{P}_{4}$ and RU486 administration on the progression and infiltration of grade III human astrocytoma cells (U373) implanted in the motor cortex of the rat. In the Nissl stained brain sections from the short progression group, we observed that, in rats treated with 


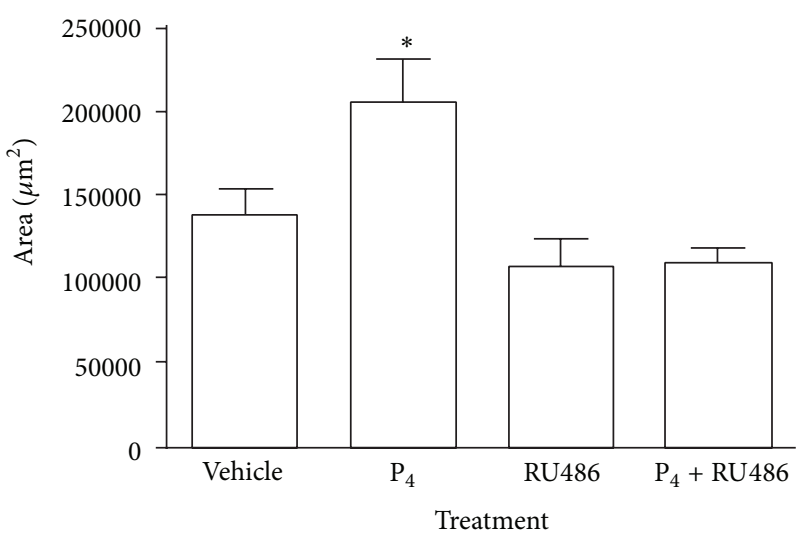

(a)

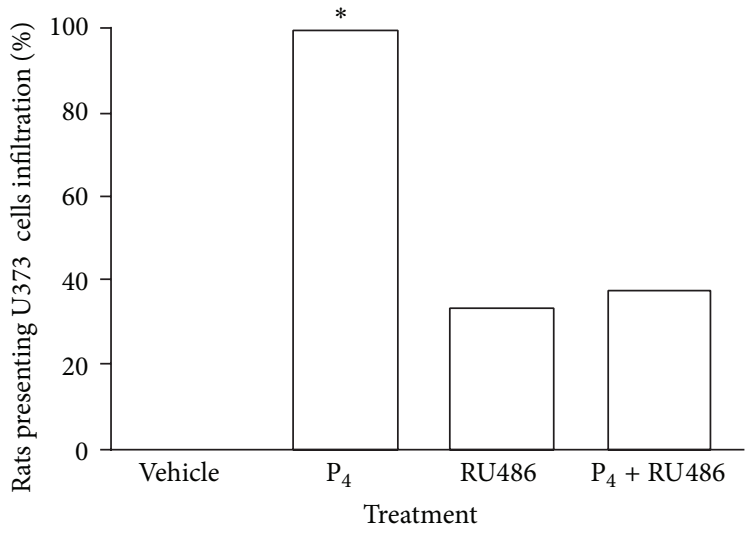

(b)

Figure 3: Effects of $\mathrm{P}_{4}$ and RU486 on the growth and infiltration of U373 cells implanted in the motor cortex of the rat. (a) Tumor area. Data represent mean \pm SEM. (b) Percentage of rats with astrocytoma cells infiltration in the brain after treatments. $n=7$. ${ }^{*} P<0.01$ versus all groups.

vehicle, U373 cells stayed around the implantation area. In this group we did not find tumor infiltration (Figure 2(a)). In rats treated with $\mathrm{P}_{4}$, we observed both significant tumor growth and infiltration to deeper structures of the brain. The average distance covered by U373 cells with this treatment was $1119 \pm 45.6 \mu \mathrm{m}$ (mean $\pm \mathrm{SEM}$ ). At the level of the corpus callosum, tissue structure was lost and we could not identify individual tumor cells; only amorphous structures were noticed (Figure 2(b)). Rats treated with RU486 (Figure 2(c)) showed a restricted tumor growth around the implant site with slight infiltration $(82.2 \pm 35.4 \mu \mathrm{m})$. U373 cells were rounded or with elongated edges and they were smaller in comparison with normal astrocytic cells (insert Figure 2(c)). Figure $2(\mathrm{~d})$ shows a representative brain section of a rat treated with $\mathrm{P}_{4}+\mathrm{RU} 486$. U373 cell morphology was diverse, showing variations in size and shape (insert Figure $2(\mathrm{~d})$ ). We observed that RU486 blocked $\mathrm{P}_{4}$ effects on tumor growth and invasion. Tumor infiltration $(121.6 \pm 43.3 \mu \mathrm{m})$ was lower than that found in the rats treated with $\mathrm{P}_{4}$ and slightly higher (nonsignificant) than in the treatment with RU486.

$\mathrm{P}_{4}$ significantly increased both the tumor area of implanted U373 cells in the cerebral cortex of the rat (Figure 3(a)) and the infiltration length. Importantly, 100\% of the rats treated with $\mathrm{P}_{4}$ showed cell migration toward deeper structures in the brain, while $28.6 \%$ and $42.9 \%$ of the animals treated with RU486 and $\mathrm{P}_{4}+$ RU486, respectively, showed it (Figure 3(b)). Although rats treated with vehicle presented a restricted tumor formation, they did not show tumor infiltration (Figure 3).

In the long progression group, despite the fact that we followed a different treatment scheme, the results of steroid administration were very similar to those of the short progression group (data not shown). Figure 4 shows immunofluorescence staining of SOX2 and Ki-67 markers on brain sections of the long progression group treated with vehicle, $\mathrm{P}_{4}$, RU486, or $\mathrm{P}_{4}+\mathrm{RU} 486$. As we observed in short progression group with brain sections stained with the Nissl method, in animals treated with vehicle, U373 cells stayed around the implant area, whereas, with $\mathrm{P}_{4}$ treatment, U373 cells migrated to deeper brain structures. In both treatments, Ki-67 and SOX 2 were colocalized in $74 \%$ and $63 \%$ of the cells, respectively. Interestingly, we found that, in rats treated with RU486, there were just few cells positive to Ki-67 (18\%) of the total cells that expressed SOX2, indicating the absence of proliferating glioma cells. Finally, in rats treated with both $\mathrm{P}_{4}$ and RU486, we noticed a decrease in U373 cells infiltration compared to those treated with $\mathrm{P}_{4}$, demonstrating that RU486 blocked $\mathrm{P}_{4}$ effects. With this treatment, Ki-67 and SOX 2 presented colocalization in $48 \%$ of the cells.

\section{Discussion}

In the present study, we analyzed the effects of $\mathrm{P}_{4}$ and its antagonist RU486 on the growth and invasion of U373 cells implanted in the motor cortex of the rat. The increase in tumor growth after $\mathrm{P}_{4}$ administration observed in our in vivo conditions is consistent with the results observed in in vitro experiments with U373 cells $[23,26]$. Additionally, it has been reported that, in $\mathrm{U} 373$ cells, $\mathrm{P}_{4}$ increases S-phase of the cell cycle [23] which could explain the increase in cell proliferation and therefore in tumor size. We also observed that RU486 blocked $\mathrm{P}_{4}$ effects, since rats treated with $\mathrm{P}_{4}$ + RU486 showed a significant decrease in tumor area in comparison with those treated with $\mathrm{P}_{4}$. These data are also consistent with previous reports in astrocytoma cell cultures $[23,26]$ and suggest that $\mathrm{P}_{4}$ effects on astrocytoma cell growth occur via the classic mechanism of action, through an interaction with PR.

$\mathrm{P}_{4}$ treatment also increased astrocytoma cells migration as well as the number of animals that presented tumor infiltration. These results have not been reported in brain tumors; however, there are studies in breast cancer indicating that $\mathrm{P}_{4}$ increases migration and invasion in MCF7 and T47D breast cancer cells and that RU486 treatment decreases migration [32]. It has been reported that progestins increase invasiveness in different cell lines of breast cancer. This 


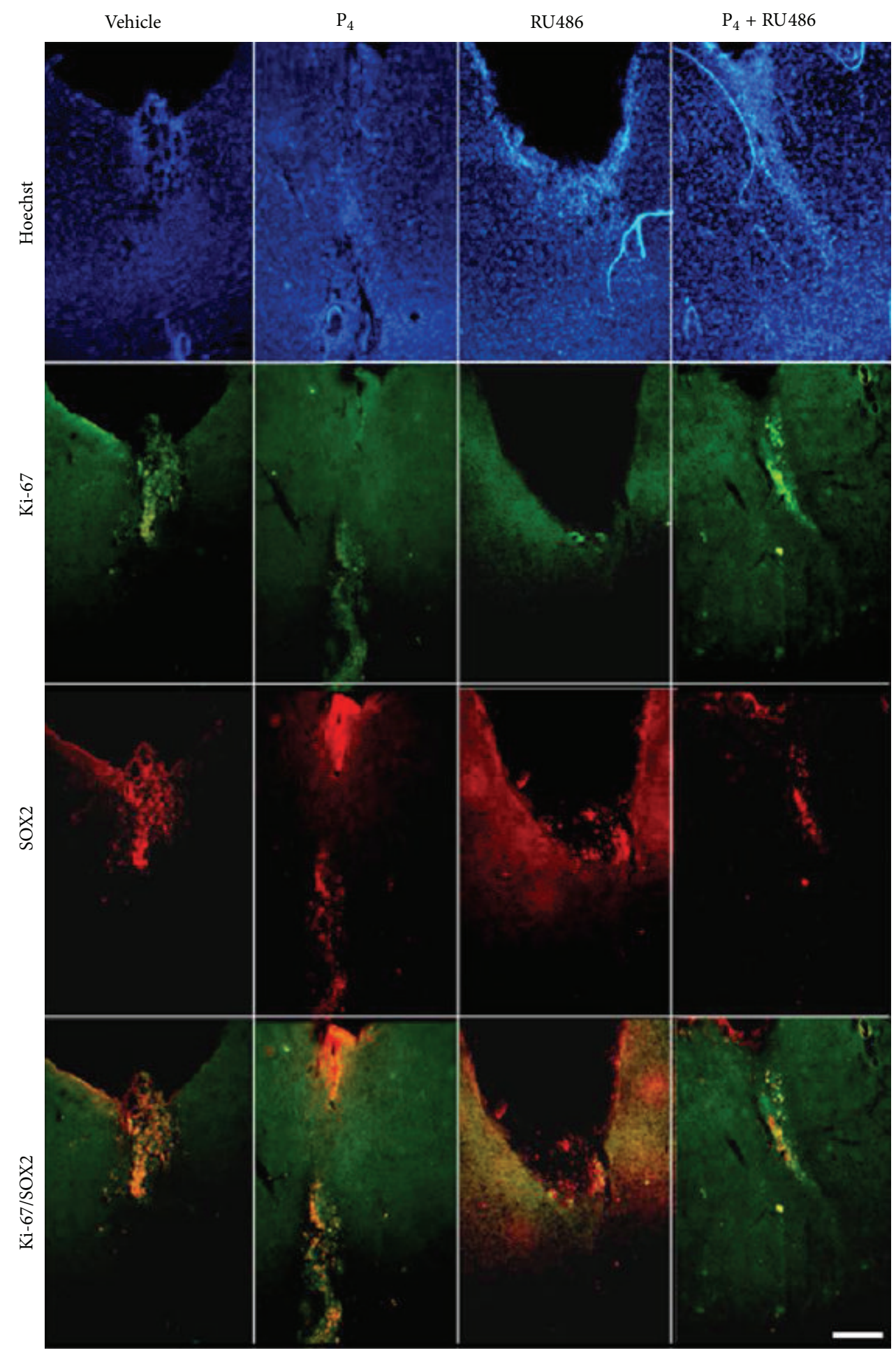

FIgURE 4: SOX2 and Ki-67 expression in U373 cells implanted in the motor cortex of rats under different treatments: vehicle, $\mathrm{P}_{4}$, RU486, or $\mathrm{P}_{4}+\mathrm{RU} 486$. Each panel shows nuclei stained with Hoechst in blue, Ki-67 expression in bright green, SOX2 expression in red, and the colocalization of Ki-67 and SOX2 in orange. Magnification is represented by $100 \mu \mathrm{m}$ scale in all photomicrographs.

effect can occur through various mechanisms, including overexpression of proteins such as superoxide dismutase, tissue factor, and protease-activated receptors [33-35]; the enhancing of matrix metalloproteinases and urokinase-type plasminogen activator activities [36]; the activating of the focal adhesion kinase [37], and the activation of rapid signaling cascades that leads to modifications in the actin cytoskeleton and the cell membrane $[38,39]$. In other several cell lines, including glioma cells, it has been found that voltage-gated ion channels play a significant role in initiation 
and progression of cancer $[40,41]$ and even some of them as the potassium voltage-gated channel are regulated by $\mathrm{P}_{4}$ [42]. In our model, we observed that RU486 blocked $\mathrm{P}_{4}$ effects on tumor infiltration, suggesting that, as in the case of tumor growth, $\mathrm{P}_{4}$ effects occur through the interaction with $\mathrm{PR}$; the precise mechanism involved in astrocytoma cells infiltration induced by $\mathrm{P}_{4}$ needs further investigation. Interestingly, although rats treated with vehicle presented a restricted growth of astrocytoma tumor area, no infiltration was observed in any rat unlike the animals treated with RU486 in which approximately $30 \%$ presented it (Figure 3). This may be due to a progestational action of RU486 that depends on the formation of specific RP dimers. Human PR presents two isoforms, PR-A and PR-B (94 and $114 \mathrm{kDa}$, resp.) with different function, regulation, and expression pattern. At basal state, PR is associated with heat shock proteins (HSP70 and HSP90) and once the hormone enters the cell, it interacts with PR and induces conformational changes that allow the dissociation of the HSP complex followed by phosphorylation and dimerization of the receptor. The active receptor possesses high affinity for specific sequences in the DNA called $\mathrm{P}_{4}$ response elements (PRE) that are found in the promoter region of $\mathrm{P}_{4}$ target genes. Once bound to PRE, PR can regulate gene transcription through the recruitment of corregulator proteins and the interaction with the basal transcription machinery [43, 44]. RU486 is a type II antagonist, which promotes PR dimerization and allows binding of the dimers to the PRE. It has been shown that RU486-bound A:A dimers are transcriptionally silent, whereas RU486-bound B:B dimers can activate transcription. RU486-bound A:B dimers act to distinctly inhibit transcriptional activation, and it is the activity that is commonly observed in $\mathrm{P}_{4}$ responsive cells $[45,46]$. It is important to mention that PR-A and PR-B isoforms have been detected in human astrocytoma cell lines and biopsies, and their expression is directly related to the tumor evolution grade. Interestingly, PR-B content is three times higher than PRA in U373 cells $[23,47]$ which could lead to an increased formation of B:B dimers and an activation of transcriptional activity upon RU486 treatment. However, the effects of this activation are significantly lower than those observed with $\mathrm{P}_{4}$ treatment. It has also been reported that, in astrocytoma tumors implanted in the cerebral cortex, the direction of migration is ventral through cortical gray matter and into the corpus callosum [48], which is consistent with our results.

Regarding the observed change in morphology of the implanted astrocytoma cells treated with RU486 (alone or in combination with $\mathrm{P}_{4}$ ), it has been reported that its administration induces alterations in the cellular structure of cancer cells of different origins (including glioblastoma cells). Such changes were associated with a redistribution of actin fibers that can form nonadhesive membrane ruffles, leading to a dysregulated cellular adhesion capacity and thereby altering the invasion capacity of these cells [49].

We observed that implanted cells expressed proliferation and glioma cells markers (Ki-67 and SOX2, resp.) and that, in many of them, both markers exhibited colocalization. These results demonstrated that the implanted U373 cells were present in the cerebral tissue of the rat and that they continued their proliferation. We also found that the percentage of Ki-67/SOX2 colocalization was higher in vehicletreated rats that in those treated with $\mathrm{P}_{4}$. This could be related to the progression of these tumors induced by $\mathrm{P}_{4}$ leading to a dedifferentiation process where the resulting cells express less proliferation markers but overexpress invasion and/or migration markers. In the case of RU486 treatment, we observed very few cells positive to $\mathrm{Ki}-67$ while those expressing SOX2 were found in a greater number. This indicates that there were glioma cells but they were not proliferating. It has been reported that RU486 induces G1-S blockage of the cell cycle in human ovarian cancer cells [50] and that RU486 reduces the activity of cdk2, enzyme that is involved in the regulation of the transcription factor E2F1 which modulates S-phase progression $[51,52]$.

\section{Conclusions}

$\mathrm{P}_{4}$ induces proliferation and infiltration of a tumor caused by the implant of human astrocytoma cells in the motor cortex of the rat through the interaction with intracellular PR.

\section{Conflict of Interests}

The authors declare that there is no conflict of interests regarding the publication of this paper.

\section{Acknowledgments}

This work was supported by Programa de Apoyo a Proyectos de Investigación e Innovación Tecnológica (PAPIIT) IN212611, DGAPA, UNAM, México.

\section{References}

[1] D. Friedmann-Morvinski, E. A. Bushong, E. Ke et al., "Dedifferentiation of neurons and astrocytes by oncogenes can induce gliomas in mice," Science, vol. 338, pp. 1080-1084, 2012.

[2] S. Alcantara Llaguno, J. Chen, C.-H. Kwon et al., "Malignant astrocytomas originate from neural stem/progenitor cells in a somatic tumor suppressor mouse model," Cancer Cell, vol. 15, no. 1, pp. 45-56, 2009.

[3] L. Cheng, S. Bao, and J. N. Rich, "Potential therapeutic implications of cancer stem cells in glioblastoma," Biochemical Pharmacology, vol. 80, no. 5, pp. 654-665, 2010.

[4] D. L. Schonberg, D. Lubelski, T. E. Miller, and J. N. Rich, "Brain tumor stem cells: molecular characteristics and their impact on therapy," Molecular Aspects of Medicine, 2013.

[5] D. Y. Cho, S. Z. Lin, W. K. Yang et al., "Targeting cancer stem cells for treatment of glioblastoma multiforme," Cell Transplant, vol. 22, pp. 731-739, 2013.

[6] D. N. Louis, H. Ohgaki, O. D. Wiestler et al., "The 2007 WHO classification of tumours of the central nervous system," Acta Neuropathologica, vol. 114, no. 2, pp. 97-109, 2007.

[7] A. Rousseau, K. Mokhtari, and C. Duyckaerts, “The 2007 WHO classification of tumors of the central nervous system-what has changed?" Current Opinion in Neurology, vol. 21, no. 6, pp. 720727, 2008. 
[8] C. Daumas-Duport, B. Scheithauer, J. O’Fallon, and P. Kelly, "Grading of astrocytomas: a simple and reproducible method," Cancer, vol. 62, no. 10, pp. 2152-2165, 1988.

[9] T. Tihan and M. M. Bloomer, "Astrocytic neoplasms of the central nervous system and orbit: a morphologic perspective," Seminars in Diagnostic Pathology, vol. 27, no. 2, pp. 114-121, 2010.

[10] L. Arko, I. Katsyv, G. E. Park, W. P. Luan, and J. K. Park, "Experimental approaches for the treatment of malignant gliomas," Pharmacology and Therapeutics, vol. 128, no. 1, pp. 1-36, 2010.

[11] A. A. Brandes, A. Tosoni, E. Franceschi, M. Reni, G. Gatta, and C. Vecht, "Glioblastoma in adults," Critical Reviews in Oncology/Hematology, vol. 67, no. 2, pp. 139-152, 2008.

[12] D. Osoba, M. Brada, W. K. A. Yung, and M. D. Prados, "Healthrelated quality of life in patients with anaplastic astrocytoma during treatment with temozolomide," European Journal of Cancer, vol. 36, no. 14, pp. 1788-1795, 2000.

[13] S. Sahebjam, M. McNamara, and W. P. Mason, "Management of glioblastoma in the elderly," Clinical Advances in Hematology and Oncology, vol. 10, pp. 379-386, 2012.

[14] K. Anton, J. M. Baehring, and T. Mayer, "Glioblastoma multiforme: overview of current treatment and future perspectives," Hematology/Oncology Clinics of North America, vol. 26, pp. 825853, 2012.

[15] R. D. Brinton, R. F. Thompson, M. R. Foy et al., "Progesterone receptors: form and function in brain," Frontiers in Neuroendocrinology, vol. 29, no. 2, pp. 313-339, 2008.

[16] I. Camacho-Arroyo and J. M. Montor, "Beyond reproductive effects of sex steroids," Mini Reviews in Medicinal Chemistry, vol. 12, pp. 1037-1039, 2012.

[17] J. D. Graham and C. L. Clarke, "Physiological action of progesterone in target tissues," Endocrine Reviews, vol. 18, pp. 502-519, 1997.

[18] J. E. Levine, P. E. Chappell, J. S. Schneider, N. C. Sleiter, and M. Szabo, "Progesterone receptors as neuroendocrine integrators," Frontiers in Neuroendocrinology, vol. 22, no. 2, pp. 69-106, 2001.

[19] M. Schumacher and R. Guennoun, "Progesterone: synthesis, metabolism, mechanisms of action, and effects in the nervous system. An overview," in Hormones, Brain and Behavior, D. W. Pfaff, A. P. Arnold, A. M. Etgen, S. E. Fahrbach, and R. T. Rubin, Eds., vol. 3, pp. 1505-1560, 2009.

[20] E. Cabrera-Muñoz, A. González-Arenas, M. Saqui-Salces et al., "Regulation of progesterone receptor isoforms content in human astrocytoma cell lines," Journal of Steroid Biochemistry and Molecular Biology, vol. 113, no. 1-2, pp. 80-84, 2009.

[21] H. Khalid, S. Shibata, M. Kishikawa, A. Yasunaga, M. Iseki, and T. Hiura, "Immunohistochemical analysis of progesterone receptor and Ki-67 labeling index in astrocytic tumors," Cancer, vol. 80, pp. 2133-2140, 1997.

[22] M. J. Riemenschneider and G. Reifenberger, "Astrocytic tumors," Recent Results in Cancer Research, vol. 171, pp. 3-24, 2009.

[23] G. González-Agüero, A. A. Gutiérrez, D. González-Espinosa et al., "Progesterone effects on cell growth of U373 and D54 human astrocytoma cell lines," Endocrine, vol. 32, pp. 129-135, 2007.

[24] G. González-Agüero, R. Ondarza, A. Gamboa-Domínguez, M. A. Cerbón, and I. Camacho-Arroyo, "Progesterone receptor isoforms expression pattern in human astrocytomas," Brain Research Bulletin, vol. 56, pp. 43-48, 2001.

[25] R. S. Carroll, J. Zhang, K. Dashner, M. Sar, P. M. Black, and C. Raffel, "Steroid hormone receptors in astrocytic neoplasms," Neurosurgery, vol. 37, no. 3, pp. 496-504, 1995.
[26] E. Cabrera-Muñoz, O. T. Hernández-Hernández, and I. Camacho-Arroyo, "Role of progesterone in human astrocytomas growth," Current Topics in Medicinal Chemistry, vol. 11, pp. 1663-1667, 2011.

[27] R. Ramaswamy, K. Ashton, R. Lea et al., "Study of effectiveness of mifepristone for glioma cell line growth suppression," British Journal of Neurosurgery, vol. 26, pp. 336-339, 2012.

[28] J. Pinski, G. Halmos, Y. Shirahige, J. L. Wittliff, and A. V. Schally, "Inhibition of growth of the human malignant glioma cell line (U87MG) by the steroid hormone antagonist RU486," Journal of Clinical Endocrinology and Metabolism, vol. 77, no. 5, pp. 13881392, 1993.

[29] M. Llaguno-Munive, L. A. Medina, R. Jurado, M. Romero-Piña, and P. Garcia-Lopez, "Mifepristone improves chemo-radiation response in glioblastoma xenografts," Cancer Cell International, vol. 13, article 29, 2013.

[30] O. T. Hernández-Hernández, T. K. González-García, and I. Camacho-Arroyo, "Progesterone receptor and SRC-1 participate in the regulation of VEGF, EGFR and Cyclin D1 expression in human astrocytoma cell lines," The Journal of Steroid Biochemistry and Molecular Biology, vol. 132, pp. 127-134, 2012.

[31] G. Paxinos and C. Watson, The Rat Brain in Stereotaxic Coordinates, Academic Press, New York, NY, USA, 4th edition, 1998.

[32] G. Epstein Shochet, S. Tartakover Matalon, L. Drucker et al., "Hormone-dependent placental manipulation of breast cancer cell migration," Human Reproduction, vol. 27, no. 1, pp. 73-88, 2012.

[33] A. K. Holley, K. K. Kiningham, D. R. Spitz, D. P. Edwards, J. T. Jenkins, and M. R. Moore, "Progestin stimulation of manganese superoxide dismutase and invasive properties in T47D human breast cancer cells," Journal of Steroid Biochemistry and Molecular Biology, vol. 117, no. 1-3, pp. 23-30, 2009.

[34] S. Kato, M. Pinto, A. Carvajal et al., "Progesterone increases tissue factor gene expression, procoagulant activity, and invasion in the breast cancer cell line ZR-75-1," Journal of Clinical Endocrinology and Metabolism, vol. 90, no. 2, pp. 1181-1188, 2005.

[35] J. Diaz, E. Aranda, S. P. Henriquez et al., "Progesterone promotes focal adhesion formation and migration in breast cancer cells through induction of protease-activated receptor 1," Journal of Endocrinology, vol. 214, no. 2, pp. 165-175, 2012.

[36] R. P. Carnevale, C. J. Proietti, M. Salatino et al., "Progestin effects on breast cancer cell proliferation, proteases activation, and in vivo development of metastatic phenotype all depend on progesterone receptor capacity to activate cytoplasmic signaling pathways," Molecular Endocrinology, vol. 21, no. 6, pp. 13351358, 2007.

[37] X.-D. Fu, L. Goglia, A. M. Sanchez et al., "Progesterone receptor enhances breast cancer cell motility and invasion via extranuclear activation of focal adhesion kinase," EndocrineRelated Cancer, vol. 17, no. 2, pp. 431-443, 2010.

[38] X.-D. Fu, M. Flamini, A. M. Sanchez et al., "Progestogens regulate endothelial actin cytoskeleton and cell movement via the actin-binding protein moesin," Molecular Human Reproduction, vol. 14, no. 4, pp. 225-234, 2008.

[39] X.-D. Fu, M. S. Giretti, L. Goglia et al., "Comparative actions of progesterone, medroxyprogesterone acetate, drospirenone and nestorone on breast cancer cell migration and invasion," $B M C$ Cancer, vol. 8, article 166, 2008.

[40] S. P. Fraser, I. Ozerlat-Gunduz, W. J. Brackenbury et al., "Regulation of voltage-gated sodium channel expression in cancer: 
hormones, growth factors and auto-regulation," Philosophical Transactions of the Royal Society of London B: Biological Sciences, vol. 369 , no. 1638, 2014.

[41] S. Wang and B. Jiao, "The inhibition of tamoxifen on sodium channel in SHG-44 glioma cell-line," Chinese Journal of Applied Physiology, vol. 25, pp. 207-210, 2009.

[42] A. Ramírez, L. M. Hinojosa, J. D. J. Gonzales et al., "KCNH1 potassium channels are expressed in cervical cytologies from pregnant patients and are regulated by progesterone," Reproduction, vol. 146, pp. 615-623, 2013.

[43] B. M. Jacobsen and K. B. Horwitz, "Progesterone receptors, their isoforms and progesterone regulated transcription," Molecular and Cellular Endocrinology, vol. 357, no. 1-2, pp. 18-29, 2012.

[44] D. P. Edwards, S. E. Wardell, and V. Boonyaratanakornkit, "Progesterone receptor interacting coregulatory proteins and cross talk with cell signaling pathways," Journal of Steroid Biochemistry and Molecular Biology, vol. 83, no. 1-5, pp. 173-186, 2002.

[45] J. Chen, J. Wang, J. Shao, and Y. Gao, “The unique pharmacological characteristics of mifepristone (RU486): from terminating pregnancy to preventing cancer metastasis," Medicinal Research Reviews, pp. 1-22, 2014.

[46] C. A. Sartorius, S. D. Groshong, L. A. Miller et al., "New T47D breast cancer cell lines for the independent study of progesterone B- and A-receptors: only antiprogestin-occupied B-receptors are switched to transcriptional agonists by cAMP," Cancer Research, vol. 54, no. 14, pp. 3868-3877, 1994.

[47] V. Hansberg-Pastor, A. González-Arenas, M. A. Peña-Ortiz, E. García-Gómez, M. Rodríguez-Dorantes, and I. CamachoArroyo, "The role of DNA methylation and histone acetylation in the regulation of progesterone receptor isoforms expression in human astrocytoma cell lines," Steroids, vol. 78, no. 5, pp. 500-507, 2013.

[48] E. R. Laws Jr., W. J. Goldberg, and J. J. Bernstein, "Migration of human malignant astrocytoma cells in the mammalian brain: scherer revisited," International Journal of Developmental Neuroscience, vol. 11, no. 5, pp. 691-697, 1993.

[49] B. N. Brandhagen, C. R. Tieszen, T. M. Ulmer, M. S. Tracy, A. A. Goyeneche, and C. M. Telleria, "Cytostasis and morphological changes induced by mifepristone in human metastatic cancer cells involve cytoskeletal filamentous actin reorganization and impairment of cell adhesion dynamics," BMC Cancer, vol. 13, article 35, 2013.

[50] A. A. Goyeneche, R. W. Carón, and C. M. Telleria, "Mifepristone inhibits ovarian cancer cell growth in vitro and in vivo," Clinical Cancer Research, vol. 13, no. 11, pp. 3370-3379, 2007.

[51] C. R. Tieszen, A. A. Goyeneche, B. N. Brandhagen, C. T. Ortbahn, and C. M. Telleria, "Antiprogestin mifepristone inhibits the growth of cancer cells of reproductive and non-reproductive origin regardless of progesterone receptor expression," $B M C$ Cancer, vol. 11, article 207, 2011.

[52] E. A. Musgrove, C. S. Lee, A. L. Cornish, A. Swarbrick, and R. L. Sutherland, "Antiprogestin inhibition of cell cycle progression in T-47D breast cancer cells is accompanied by induction of the cyclin-dependent kinase inhibitor p21," Molecular Endocrinology, vol. 11, pp. 54-66, 1997. 




The Scientific World Journal
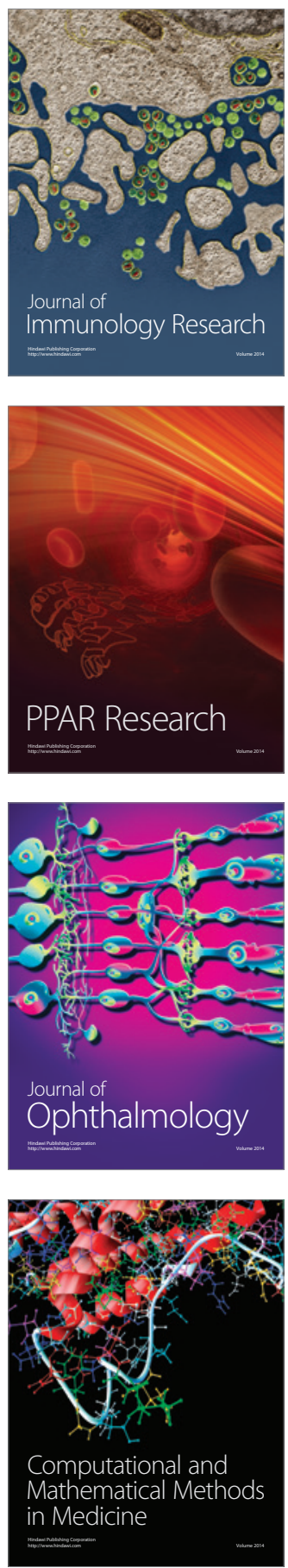

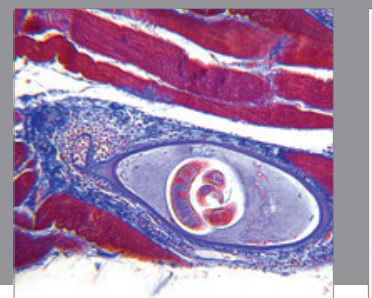

Gastroenterology

Research and Practice
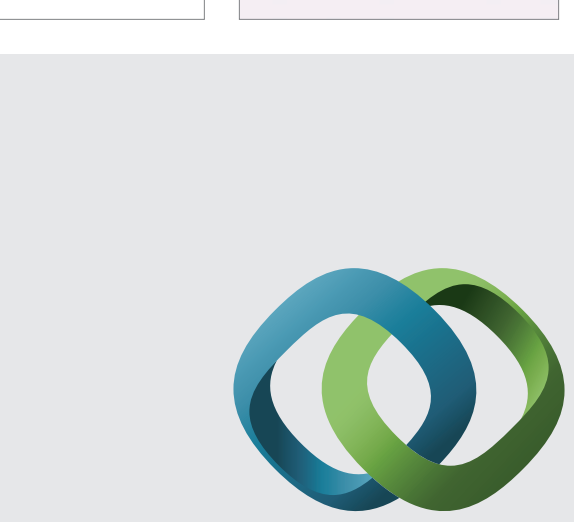

\section{Hindawi}

Submit your manuscripts at

http://www.hindawi.com
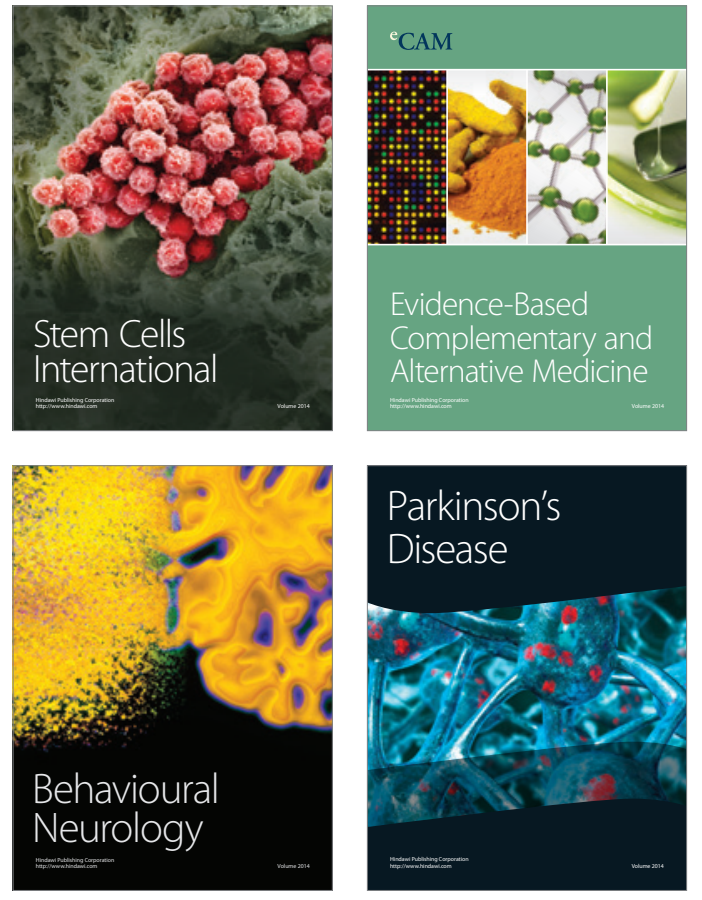
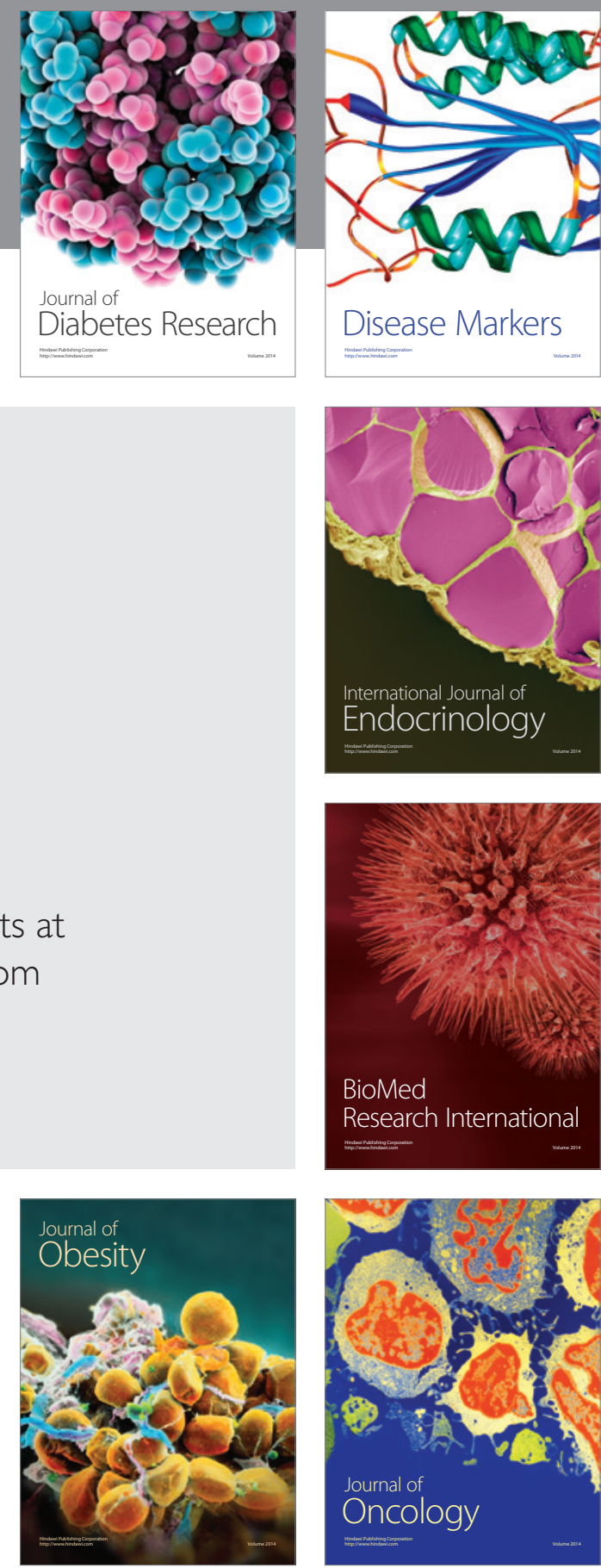

Disease Markers
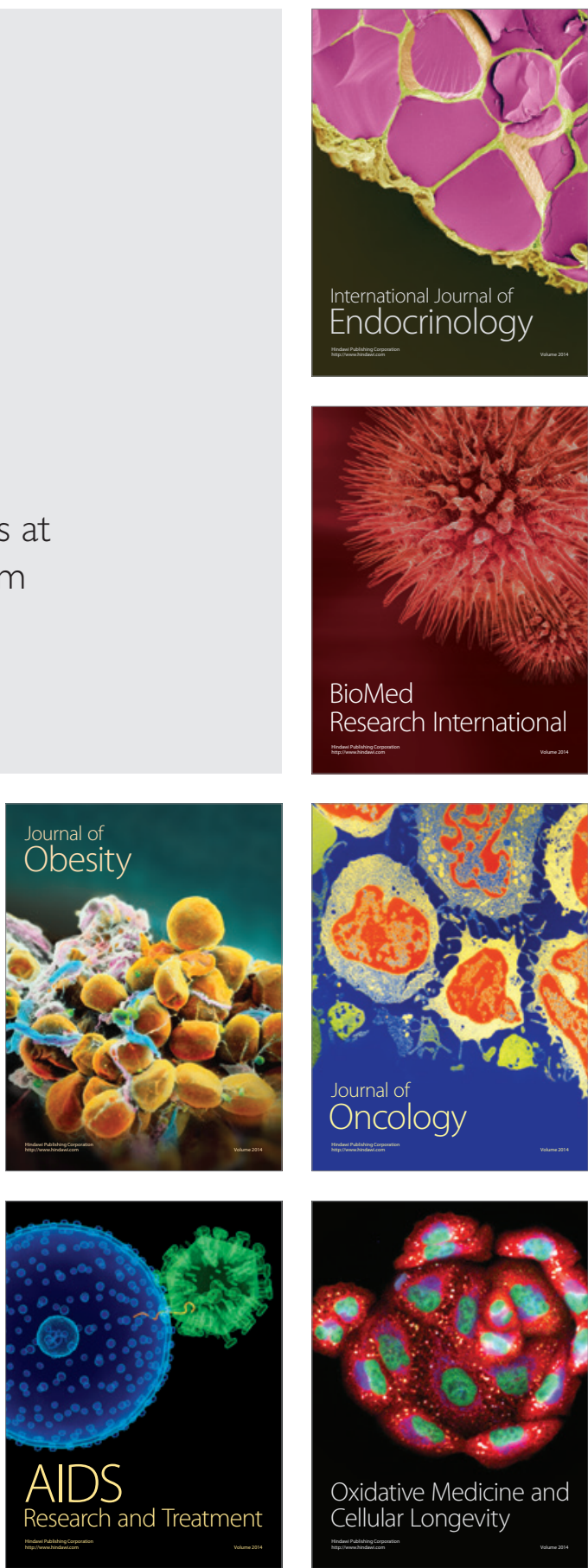